\title{
Application of biochar-coated urea controlled loss of fertilizer nitrogen and increased nitrogen use efficiency
}

Yiman Jia ${ }^{1}$, Zhengyi $\mathrm{Hu}^{1,2,3^{*}} \mathbb{C}$, Yuxin $\mathrm{Ba}^{4}$ and Wenfang $\mathrm{Qi}^{5}$

\begin{abstract}
Background: The use of biochar-based $\mathrm{N}$ fertilizers have been considered among the most effective strategy for reducing nitrogen loss and improving nitrogen use efficiency (NUE). However, effect and mechanism of biocharcoated urea (BCU) controlling the loss of nitrogen from soil and NUE are rarely reported.

Methodology: In this study, a 65-d culture pot experiment of oilseed rape was used to investigate the impact of BCU on nitrogen leaching, ammonia volatilization, soil nitrogen concentrations, soil pH, nitrogen uptake, NUE and oilseed rape biomass as compared with urea and urea combined with biochar at same nitrogen level.

Results: Results showed that the application of BCU could minimize nitrogen loss mainly by reducing nitrate leaching loss; which could be attributed to the slow-release performance of BCU, followed by biochar induced adsorption/ fixation of nitrogen due to the porous nature and surface functional groups of biochar. However, the application of $\mathrm{BCU}$ enhanced ammonia volatilization due to the increase of soil $\mathrm{NH}_{4}{ }^{+}-\mathrm{N}$ concentration and $\mathrm{pH}$ value of microenvironment around urea by BCU. The application of BCU increased NUE by about $20 \%$ when compared with urea, since $\mathrm{BCU}$ reduced losses of nitrogen fertilizer and increased concentration of nitrogen in the soil as well as nitrogen uptake in oilseed rape. Furthermore, the reduction of nitrogen application by $20 \%$ when BCU served as a nitrogen source not only reduced nitrogen loss but significantly improved NUE, with no negative effect on the biomass of oilseed rape.
\end{abstract}

Conclusion: BCU can serve as a promising control release nitrogen fertilizer for reducing loss of nitrogen and increasing NUE. However further investigations are required to validate the dosage-effect relationship of BCU on crop yield at the field scale.

Keywords: Biochar, Biochar-based fertilizer, Slow-release coated urea, Ammonia volatilization, Nitrogen leaching, Nitrogen use efficiency

\section{Background}

The large amount application of nitrogen fertilizer has made great contribution to satisfy the continuously increasing food demand in China. However, loss of nitrogen fertilizer from soils of farmland via runoff, leaching, and ammonia volatilization, etc. $[1,2]$ not only results in the low nitrogen use efficiency (NUE) and high

\footnotetext{
*Correspondence: zhyhu@ucas.ac.cn

${ }^{1}$ College of Resources and Environment, University of Chinese Academy

of Sciences, Beijing 101408, China

Full list of author information is available at the end of the article
}

production cost, but also increases environmental risk, since large amounts of nitrogen from agricultural fields may deposit in neighbouring ecosystems and lead to acidification and eutrophication of natural ecosystems [3-6]. Application of nitrogen in China averages $305 \mathrm{~kg} \mathrm{~N}$ per ha compared to $74 \mathrm{~kg} \mathrm{~N}$ per ha worldwide, but nitrogen use efficiency is only $25 \%$ compared to $42 \%$ worldwide [ 7 , 8]. Therefore, how to control the loss of nitrogen nutrient and further improve the NUE have become a major concern in agricultural production in China.

Biochar, the product of thermal degradation of biomass resources in the absence of air (pyrolysis), has 
several properties that make it an efficient material to reduce nitrogen loss and improve NUE [9-11]. Beck et al. observed that the $\mathrm{NO}_{3}{ }^{-}-\mathrm{N}$ and total nitrogen loss from soil through runoff was reduced by $97 \%$ and $87 \%$, respectively, when applying $7 \%$ mixed material biochar (walnut shell, rice shell, coconut shell, etc.) into ryegrass trays [12]. The reduction of nitrogen loss and improvement of NUE could be attributed to the porosity, large specific surface area, surface charges, variety of surface functional groups and a small amount of active carbon present in biochar [13-15]. These properties of biochar could increase soil water holding capacity, adsorp inorganic nitrogen, influence nitrification and denitrification of nitrogen in soil, increase microbial biomass, and change soil structure of bacterial community [16-19].

The application of biochar can be either direct into soil or in the form of biochar-based fertilizer. Direct application is the simplest and most convenient way $[20,21]$. However, the storage, transportation and soil application of biochar are challenging because biochar is brittle, or has wide particle size distribution and low density [22]. Furthermore, a single amount of biochar for soil amendment at high rates of 20-50 $\mathrm{t} \mathrm{ha}^{-1}$, makes the economic feasibility for farmers questionable [23]. Biochar-based fertilizers are prepared by mixing biochar with inorganic fertilizer using physical or chemical methods (biochar-mixed fertilizer) [24-26] or coating biochar with binder outside inorganic fertilizer particles (biochar-coated fertilizer) [27-29]. Shi et al. prepared a granular biochar-mineral urea composite (Bio-MUC) by blending urea with green waste biochar supplemented with clay minerals of bentonite and sepiolite and observed that cumulative $\mathrm{N}$ release as $\mathrm{NH}_{4}{ }^{+}-\mathrm{N}$ was significantly smaller by $>70 \%$ from Bio-MUC than from urea in the leaching experiment over 30 days [25]. Wang et al. observed that nitrogen loss, ammonia volatilization and leaching nitrogen was $43.5 \%-45.5 \%, 3.7 \%-21.7 \%$ and $49.8 \%-52.1 \%$ lower respectively after application of BCU than urea at nitrogen application rates of 320 and $280 \mathrm{mg} \mathrm{N} / \mathrm{kg}$ soil in pot experiment [29]. Our previous studies have successfully developed a series of BCU with satisfactory nitrogen slow release performance [15]. However, effects of biochar-coated urea on loss of nitrogen fertilizer and nitrogen use efficiency need to be validated.

The present objectives were to (1) investigate the characteristics of nitrogen fertilizer loss in soil applying BCU and NUE under vegetable-growing condition; (2) compare effects of nitrogen loss and NUE between $\mathrm{BCU}$ and urea; (3) compare effects of nitrogen loss and NUE between BCU and BCU combined with biochar. It is anticipated that the present work will provide a measure for controlling agricultural non-point source pollution and introduce a new option for the high-value utilization of biochar prepared by pyrolysis of biomass resources.

\section{Materials and methods Materials}

Biochar used for BCU was prepared based on pyrolysis of vinasse in a fixed-bed heating furnace. The pyrolysis temperature was $600{ }^{\circ} \mathrm{C}$ and the pyrolysis time was $90 \mathrm{~min}$. The $\mathrm{pH}$, specific surface area, ash content, $\mathrm{C}$ content, $\mathrm{H}$ content, $\mathrm{N}$ content, $\mathrm{O}$ content, $\mathrm{O} / \mathrm{C}$ molar ratio, and $\mathrm{H} / \mathrm{C}$ molar ratio of biochar were $8.88,172.48 \mathrm{~g} / \mathrm{m}^{2}, 29.89 \%$, $61.32 \%, 1.62 \%, 2.79 \%, 1.66 \%, 0.02,0.32$, respectively. The microstructure, surface functional groups and carbon structures of biochar are presented in Additional file 1: Figs. S1-S3, respectively. BCU was manufactured by coating biochar outside urea with a coating machine [15, 30] (Fig. 1); First, urea was added to a coating machine which was already in operation at a speed of $80 \mathrm{rpm}$; Then, biochar and oxidized starch were sprayed into the machine in batches to coat biochar on the urea particles; Finally, resin and paraffin were coated outside the biochar layer by a spiral oscillator and a high-pressure spray gun, respectively. The percent of biochar in BCU was $22.56 \%$. The nitrogen content of $\mathrm{BCU}$ was $33.67 \%$. The carbon content of $\mathrm{BCU}$ was $31.53 \%$. The nitrogen release properties of BCU were presented in our previous study [15].

The soil for the pot experiment was red soil containing $2.1 \%$ organic matter, $56.73 \mathrm{mg} \mathrm{kg}^{-1}$ total nitrogen, $3.54 \mathrm{mg} \mathrm{kg}^{-1}$ available phosphorous, $3.54 \mathrm{mg} \mathrm{kg}^{-1}$ available potassium and a $\mathrm{pH}$ of 5.94. Calcium superphosphate $\left(\mathrm{CaP}_{2} \mathrm{H}_{4} \mathrm{O}_{8}\right)$ was used as phosphate fertilizer and potassium sulfate $\left(\mathrm{K}_{2} \mathrm{SO}_{4}\right)$ as potash fertilizer.

\section{Pot experiment design}

In this study, a pot experiment was conducted with eight treatments composed of two sources of nitrogen fertilizer, two rates of nitrogen fertilization and biochar (Table 1). In detail, No fertilizer (CK), urea at $100 \% \mathrm{~N}$ rate (U1), urea at $80 \% \mathrm{~N}$ rate (U2), biochar combined with urea at $100 \% \mathrm{~N}$ rate $(\mathrm{U} 1+\mathrm{B})$, biochar combined with urea at $80 \% \mathrm{~N}$ rate $(\mathrm{U} 2+\mathrm{B})$, biochar-coated urea at $100 \% \mathrm{~N}$ rate (BCU1), biochar-coated urea at $80 \%$ $\mathrm{N}$ rate (BCU2), and biochar combined with biocharcoated urea at $100 \% \mathrm{~N}$ rate $(\mathrm{BCU} 1+\mathrm{B})$. Specifically, the amount of biochar added to the soil in the treatment of $\mathrm{U} 1+\mathrm{B}$ and $\mathrm{U} 2+\mathrm{B}$ was calculated according to the economic index cost of biochar and urea equivalent applied to the soil in the treatment of $\mathrm{U} 1+\mathrm{B}$ and $\mathrm{U} 2+\mathrm{B}$ were equivalent to that of $\mathrm{BCU} 1$ and $\mathrm{BCU} 2$ at the same $\mathrm{N}$ dose. The total amount of biochar added by $\mathrm{BCU} 1+\mathrm{B}$ was the same as $\mathrm{U} 1+\mathrm{B}$. All these treatments were applied with $160 \mathrm{mg} / \mathrm{kg} \mathrm{P}\left(366.4 \mathrm{mg} / \mathrm{kg} \mathrm{P}_{2} \mathrm{O}_{5}\right)$ and 
$62 \mathrm{mg} / \mathrm{kg} \mathrm{K}\left(74.4 \mathrm{mg} / \mathrm{kg} \mathrm{K}_{2} \mathrm{O}\right)$. Each treatment was performed in triplicate.

The plastic pots were $20 \mathrm{~cm}$ in diameter and $14 \mathrm{~cm}$ in height, which were loaded from bottom to top with 100 mesh gauze, $1.5 \mathrm{~cm}$ of gravel (to cover the drain hole), $8.5 \mathrm{~cm}$ of soil (1500 g soil), and $3 \mathrm{~cm}$ of soil mixed with nitrogen, biochar, phosphate and potassium fertilizers (500 g soil), respectively. A plastic tray was placed at the bottom of each pot for collecting the leaching water. Ten four-day-old rapeseed seedlings (B. campestris L.) were transplanted to each plastic pot, and keeping five seedlings per pot on the 24th day of transplanting. Quantitative irrigation was carried out during the experiment using purified water for $500 \mathrm{ml}$ each time. The positions of plastic pots were changed successively every day to reduce the error brought by position differences. The pot experiment lasted for $65 \mathrm{~d}$.

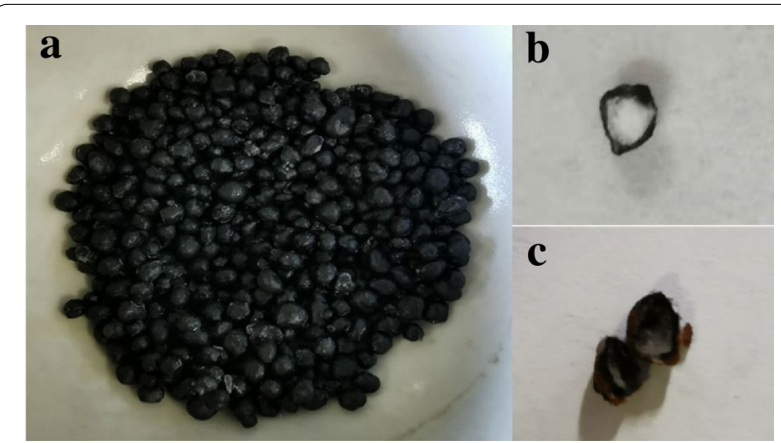

Fig. 1 Pictures of biochar-coated urea. a biochar-coated urea; $\mathbf{b}$ tangent plane of biochar-coated urea; $\mathbf{c}$ tangent plane of biochar-coated urea from soil after oilseed rape harvest

\section{Sample collection and analysis}

Volatilized ammonia was collected by closed chamber absorption method [29]. The schematic plot of ammonia volatilization collection was shown in Additional file 1: Fig. S4. Volatilized ammonia was absorbed by dilute sulfuric acid $(0.01 \mathrm{~mol} / \mathrm{L})$ from the first day after fertilization and once a day for a total of $8 \mathrm{~h}$ each time. The ammonia volatilization every day was calculated by multiply the measured ammonia volatilization by three. The collection was stopped when the amount of ammonia volatilization under nitrogen fertilization treatments were similar to that under CK treatment for several consecutive days. The ammonium nitrogen of the absorption solutions was determined with the sodium salicylic hypochlorite spectrophotometry method (HJ 536-2009).

Watering for seven times was carried out during the whole pot experiment. The water flowing into the plastic tray was collected as leaching solution on the day of watering for analysis of $\mathrm{TN}, \mathrm{NH}_{4}{ }^{+}-\mathrm{N}$ and $\mathrm{NO}_{3}{ }^{-}-\mathrm{N}$. The volume of the leaching solutions was measured with a measuring cylinder.

At the end of the experiment, all the harvested oilseed rape plants were washed and dried in an oven at $105{ }^{\circ} \mathrm{C}$ for $30 \mathrm{~min}$, and then dried at $80{ }^{\circ} \mathrm{C}$ to constant weight for estimation of the plant biomass. The dried plants were then ground for nitrogen analysis. The soil in each pot was thoroughly mixed, and part of the soil was taken for the determination of soil $\mathrm{pH}, \mathrm{TN}, \mathrm{NH}_{4}^{+}-\mathrm{N}$ and $\mathrm{NO}_{3}{ }^{-}-\mathrm{N}$.

The total nitrogen in solutions collected was determined with the alkaline potassium persulfate digestionultraviolet spectrophotometric method (HJ 636-2012); The total nitrogen in plant and soil was determined with 5E-CHN2000 elemental analyzer (Changsha kaiyuan

Table 1 Rates of applied nitrogen fertilizer as urea or biochar-coated urea and biochar or biochar in biochar-coated urea in soils

\begin{tabular}{|c|c|c|c|c|c|c|}
\hline Treatment & $\begin{array}{l}\text { Nitrogen } \\
\text { application rate } \\
(\mathrm{mg} / \mathrm{kg})\end{array}$ & $\begin{array}{l}\text { Equal amount } \\
\text { of nitrogen used } \\
\text { in field ( } \mathrm{kg} / \mathrm{ha})\end{array}$ & $\begin{array}{l}\text { Percent of biochar } \\
\text { applied in soil (\%) }\end{array}$ & $\begin{array}{l}\text { Amount of urea } \\
\text { applied in soil (g/ } \\
\text { pot) }\end{array}$ & $\begin{array}{l}\text { Amount of biochar } \\
\text { applied in soil (g/ } \\
\text { pot) }\end{array}$ & $\begin{array}{l}\text { Amount of BCU } \\
\text { applied in soil (g/ } \\
\text { pot) }\end{array}$ \\
\hline CK & - & & - & - & - & - \\
\hline U1 & 200 & 450 & - & 0.881 & - & - \\
\hline U2 & 160 & 360 & - & 0.705 & - & - \\
\hline$U 1+B$ & 200 & 450 & 0.5 & 0.881 & 10 & - \\
\hline$U 2+B$ & 160 & 360 & 0.5 & 0.705 & 10 & - \\
\hline BCU1 & 200 & 450 & 0.013 & - & 0.261 & 1.188 \\
\hline $\mathrm{BCU} 2$ & 160 & 360 & 0.010 & - & 0.209 & 0.950 \\
\hline$B C U 1+B$ & 200 & 450 & 0.5 & - & 10 & 1.188 \\
\hline
\end{tabular}

CK, no fertilizer; $\mathrm{U} 1$, urea at $100 \% \mathrm{~N}$ rate; $\mathrm{U} 2$, urea at $80 \% \mathrm{~N}$ rate; $\mathrm{U} 1+\mathrm{B}$, biochar combined with urea at $100 \% \mathrm{~N}$ rate; $\mathrm{U} 2+\mathrm{B}, \mathrm{biochar}$ combined with urea at $80 \% \mathrm{~N}$ rate; $\mathrm{BCU} 1$, biochar-coated urea at $100 \% \mathrm{~N}$ rate; $\mathrm{BCU} 2$, biochar-coated urea at $80 \% \mathrm{~N}$ rate; $\mathrm{BCU} 1+\mathrm{B}$, biochar combined with biochar-coated urea at $100 \% \mathrm{~N}$ rate

Amount of biochar applied in soil for BCU1 + B treatment included $0.261 \mathrm{~g} /$ pot of biochar from coating material in biochar-coated urea and $9.739 \mathrm{~g} /$ pot of biochar powder 
instruments Co., Ltd., China); $\mathrm{NH}_{4}{ }^{+}-\mathrm{N}$ in solutions was determined with the sodium salicylic hypochlorite spectrophotometry method (HJ 536-2009); and $\mathrm{NO}_{3}{ }^{-}-\mathrm{N}$ in solutions was determined with the dual-wavelength ultraviolet spectrophotometric method (HJ/T 346-2007).

\section{Data treatment and statistical analysis}

The nitrogen absorption amount of oilseed rape was calculated with Eq. (1):

$$
M_{N R}=C_{N R} \times M_{R}
$$

where $\mathrm{M}_{\mathrm{NR}}$ is the nitrogen absorption amounts (mg/pot) of oilseed rape; $\mathrm{C}_{\mathrm{NR}}$ is nitrogen concentration of oilseed rape (\%); $M_{R}$ is the oilseed rape biomass (mg/pot).

The NUE was calculated with Eq. (2):

$$
E_{N}=100 \times\left(M_{N R F}-M_{N R C}\right) / M_{N}
$$

where $E_{N}$ is the NUE (\%); $M_{N R F}$ is the nitrogen absorption amount $(\mathrm{mg} / \mathrm{pot})$ of oilseed rape with fertilized treatments (mg/pot); $\mathrm{M}_{\mathrm{NRC}}$ is the nitrogen absorption amount (mg/pot) of oilseed rape with CK treatments (mg/pot); $\mathrm{M}_{\mathrm{N}}$ is the amount of nitrogen application (mg/pot).

Graphical analysis was carried out using OriginPro 9.0 (OriginLab Corporation, Northampton, MA, USA). Statistical analyses (two-way ANOVA) were performed using SPSS Version 19.0 software (SPSS Inc., Chicago, USA). The least significant difference (LSD) was used to test for significance at $p<0.05$ between the means.

\section{Results}

\section{Effect of BCU application on ammonia volatilization}

Ammonia volatilization was observed in all treated

\begin{tabular}{|c|c|c|c|}
\hline Treatments & $\mathrm{NH}_{4}{ }^{+}-\mathrm{N}$ & $\mathrm{NO}_{3}{ }^{-}-\mathrm{N}$ & total nitrogen \\
\hline CK & $0.38 \pm 0.04 e$ & $7.93 \pm 0.98 d$ & $6.34 \pm 2.19 f$ \\
\hline U1 & $4.47 \pm 0.63 a$ & $60.62 \pm 0.61 a$ & $78.03 \pm 7.50 \mathrm{a}$ \\
\hline U2 & $3.95 \pm 0.55 \mathrm{ab}$ & $55.31 \pm 5.11 \mathrm{ab}$ & $67.65 \pm 1.23 b$ \\
\hline$U 1+B$ & $4.08 \pm 0.21 \mathrm{ab}$ & $57.11 \pm 5.21 a$ & $74.95 \pm 6.15 \mathrm{ab}$ \\
\hline $\mathrm{U} 2+\mathrm{B}$ & $3.62 \pm 0.03 b$ & $45.68 \pm 7.28 c$ & $57.78 \pm 6.10 c$ \\
\hline BCU1 & $2.74 \pm 0.35 c$ & $48.61 \pm 4.58 \mathrm{bc}$ & $49.81 \pm 2.33 \mathrm{~cd}$ \\
\hline BCU2 & $2.10 \pm 0.29 d$ & $41.67 \pm 5.36 c$ & $42.94 \pm 4.89 \mathrm{de}$ \\
\hline$B C U 1+B$ & $1.68 \pm 0.04 d$ & $40.44 \pm 2.89 c$ & $41.35 \pm 2.59 e$ \\
\hline
\end{tabular}
soils from the first day of the pot experiment (Fig. 2a).

$\mathrm{CK}$, no fertilizer; $\mathrm{U} 1$, urea at $100 \% \mathrm{~N}$ rate; $\mathrm{U} 2$, urea at $80 \% \mathrm{~N}$ rate; $\mathrm{U} 1+\mathrm{B}$, biochar combined with urea at $100 \% \mathrm{~N}$ rate; $\mathrm{U} 2+\mathrm{B}$, biochar combined with urea at $80 \%$ $\mathrm{N}$ rate; $\mathrm{BCU1}$, biochar-coated urea at $100 \% \mathrm{~N}$ rate; $\mathrm{BCU} 2$, biochar-coated urea at $80 \% \mathrm{~N}$ rate; $\mathrm{BCU} 1+\mathrm{B}$, biochar combined with biochar-coated urea at $100 \%$ $\mathrm{N}$ rate

Different letters in the same column indicate a significant difference at the $5 \%$ level according to the LSD test
Ammonia volatilization from $\mathrm{CK}$ continued until the 7 th day of the experiment; from soils fed with urea until the 23th-25th day of the experiment (from U2 and $\mathrm{U} 2+\mathrm{B}$ until the 25th day; from soils fed with $\mathrm{U} 1$ and $\mathrm{U} 1+\mathrm{B}$ until the 23th day, and the 24th day, respectively); from soils fed with biochar-coated urea (BCU1,BCU2, $\mathrm{BCU} 1+\mathrm{B})$ until at least the 26th day of the experiment (Fig. 2a). The five obvious peaks of ammonia volatilization were observed from soils fed with biochar-coated urea $(\mathrm{BCU} 1, \mathrm{BCU} 2, \mathrm{BCU} 1+\mathrm{B})$ at the 5 th day and 7 th day, 9th day, 13th day, and 15th day of the experiment compared to only two peaks from soils fed with urea at the 5th day and 7th day of the experiment (U1, U2, $\mathrm{U} 1+\mathrm{B}, \mathrm{U} 2+\mathrm{B})$ (Fig. 1a). The highest peak of ammonia volatilization in $\mathrm{U} 1$ and $\mathrm{U} 2$ treatments appeared on the 5th day of experiment; in $\mathrm{U} 1+\mathrm{B}$ and $\mathrm{U} 2+\mathrm{B}$ treatments on the 5th day and the 7th day of experiment, respectively; in $\mathrm{BCU} 1, \mathrm{BCU} 2$, and $\mathrm{BCU} 1+\mathrm{B}$ treatments on the 5th day, the 7th day and the 15th day of experiment, respectively (Fig. 1a). The highest peak values of ammonia volatilization followed the decreasing order as bellow: $\mathrm{BCU} 1>\mathrm{U} 1>\mathrm{U} 1+\mathrm{B} ; \quad \mathrm{U} 2, \quad \mathrm{BCU} 2>\mathrm{U} 2+\mathrm{B}$; BCU1 + B > U1 + B; U1 > U2 (Fig. 2a).

The cumulative ammonia volatilization followed the decreasing order as bellow: $\mathrm{BCU} 2>\mathrm{U} 2>\mathrm{U} 2+\mathrm{B}$; $\mathrm{BCU} 1>\mathrm{U} 1>\mathrm{U} 1+\mathrm{B} ; \quad \mathrm{BCU} 1+\mathrm{B}>\mathrm{U} 1+\mathrm{B}$. The highest cumulative ammonia volatilization $(7.21-8.98 \mathrm{mg} / \mathrm{kg}$ ) among treatments were observed from soils fed with biochar-coated urea, the lowest cumulative ammonia volatilization $(3.39-3.91 \mathrm{mg} / \mathrm{kg}$ ) among treatments were observed from soils fed with biochar combined with urea (Fig. 1b). Reduction rate of nitrogen fertilization as BCU by $20 \%$ (BCU2) was observed to reduce the cumulative ammonia volatilization by $24.42 \%$.

\section{Effect of BCU application on leaching loss of nitrogen in soil}

Leaching loss of $\mathrm{NH}_{4}{ }^{+}-\mathrm{N}, \mathrm{NO}_{3}{ }^{-}-\mathrm{N}$ and total nitrogen were observed in all treatments during experiment, which gradually increased, and reached a maximum, and then gradually decreased (Fig. 2). The cumulative leaching loss of $\mathrm{NH}_{4}{ }^{+}-\mathrm{N}, \mathrm{NO}_{3}{ }^{-}-\mathrm{N}$ and total nitrogen in $\mathrm{CK}$ were significantly lower than other fertilization treatments during the whole pot experiment (Fig. 3, Table 2).

The greatest peak of leaching loss of $\mathrm{NH}_{4}{ }^{+}-\mathrm{N}$ from CK appeared on the 25th day of experiment (the third watering event), the greatest peak of leaching loss of $\mathrm{NH}_{4}{ }^{+}-\mathrm{N}$ from soil fed with urea $(\mathrm{U} 1, \mathrm{U} 1+\mathrm{B}, \mathrm{U} 2+\mathrm{B})$ on the 17th day of experiment (the 2nd watering event) excepting for U2, the greatest peak of leaching loss of $\mathrm{NH}_{4}^{+}-\mathrm{N}$ from soil fed with biochar-coated urea $(\mathrm{BCU} 1, \mathrm{BCU} 1+\mathrm{B}, \mathrm{BCU} 1+\mathrm{B})$ on the 25 th day of experiment (the third watering event) (Fig. 3a). 
The cumulative loss of $\mathrm{NH}_{4}^{+}-\mathrm{N}$ was lower from soils fed with biochar-coated urea (BCU1, BCU1+B, $\mathrm{BCU} 1+\mathrm{B})$ than from soils fed with urea (U1, U2, $\mathrm{U} 1+\mathrm{B}, \mathrm{U} 2+\mathrm{B})$ irrespective of $\mathrm{N}$ levels. Under the same level of nitrogen fertilization, the cumulative leaching loss of $\mathrm{NH}_{4}{ }^{+}-\mathrm{N}$ in soils fed with BCU (BCU1, BCU2) were $38.67 \%-46.95 \%$ lower than that in soils fed with urea (U1, U2), which were $32.74 \%-42.22 \%$ lower than that in soils fed with urea mixed biochar $(\mathrm{U} 1+\mathrm{B}, \mathrm{U} 2+\mathrm{B})$. The cumulative loss of $\mathrm{NH}_{4}{ }^{+}-\mathrm{N}$ was $11.17-23.68 \%$ lower from soils fed with low $\mathrm{N}$ level than from soils fed with high $\mathrm{N}$ level. The cumulative loss of $\mathrm{NH}_{4}{ }^{+}-\mathrm{N}$ was $58.85 \%$ lower from soil fed with $\mathrm{BCU} 1+\mathrm{B}$ than from soil fed with $\mathrm{U} 1+\mathrm{B}$ (Fig. 3a, Table 2).

The greatest peak of leaching loss of $\mathrm{NO}_{3}{ }^{-}-\mathrm{N}$ from all treatments appeared on the 57th day of experiment (the 6th watering event) except for U1 treatment (Fig. 3b). The leaching loss of $\mathrm{NO}_{3}{ }^{-}-\mathrm{N}$ mainly occurred after 25 days of experiment (the third watering event), which accounted for more than $90 \%$ of the cumulative
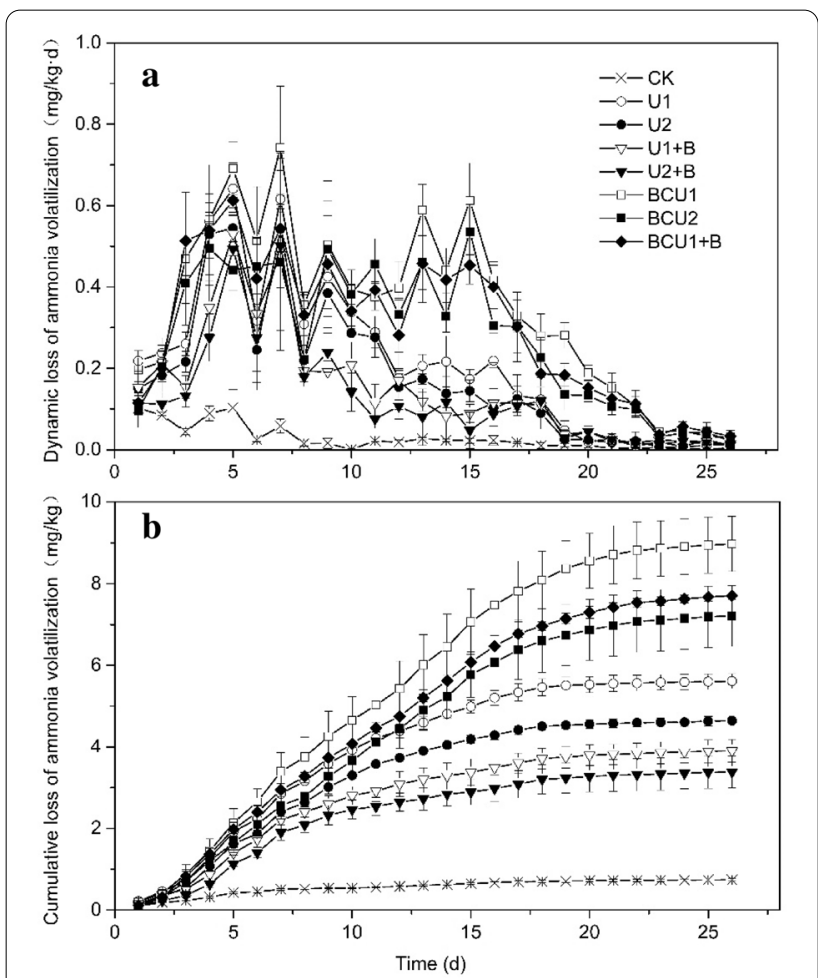

Fig. 2 Dynamics and cumulative loss of $\mathrm{NH}_{3}$ volatilization in different fertilized soils. a dynamic loss; $\mathbf{b}$ cumulative loss. CK, no fertilizer; $\mathrm{U} 1$, urea at $100 \% \mathrm{~N}$ rate; $\mathrm{U} 2$, urea at $80 \% \mathrm{~N}$ rate; $\mathrm{U1}+\mathrm{B}$, biochar combined with urea at $100 \% \mathrm{~N}$ rate; $\mathrm{U} 2+\mathrm{B}$, biochar combined with urea at $80 \% \mathrm{~N}$ rate; $\mathrm{BCU1}$, biochar-coated urea at $100 \% \mathrm{~N}$ rate; $\mathrm{BCU} 2$, biochar-coated urea at $80 \% \mathrm{~N}$ rate; $\mathrm{BCU} 1+\mathrm{B}$, biochar combined with biochar-coated urea at $100 \% \mathrm{~N}$ rate. Error bars represent $\pm s d(n=3)$ leaching loss of $\mathrm{NO}_{3}{ }^{-}-\mathrm{N}$ during the whole experiment (Fig. 3b).Under the same level of nitrogen fertilizer, the cumulative leaching loss of $\mathrm{NO}_{3}{ }^{-}-\mathrm{N}$ in soils fed with BCU (BCU1, BCU2) were significantly lower than that in soils fed with urea (U1, U2) (Table 2). Under the same level of nitrogen fertilizer, the cumulative leaching loss of $\mathrm{NO}_{3}{ }^{-}-\mathrm{N}$ was $19.8 \%$ and $24.7 \%$ lower from soils fed with BCU1 and BCU2 than from soils fed with U1 and U2, respectively (Table 2); which was lower from soil fed with urea combined with biochar $(\mathrm{U} 1+\mathrm{B}, \mathrm{U} 2+\mathrm{B})$ than from soils fed with urea $(\mathrm{U} 1, \mathrm{U} 2)$. The cumulative leaching loss of $\mathrm{NO}_{3}{ }^{-}-\mathrm{N}$ from soils was lower with $\mathrm{U} 1+\mathrm{B}$ treatment than with $\mathrm{U} 1$ treatment, but the difference was not significant $(p<0.05)$; which was lower with $\mathrm{BCU} 1+\mathrm{B}$ treatment than with $\mathrm{U} 1+\mathrm{B}$ treatment, with significant difference $(p<0.05)$ (Table 2).

The leaching trend of total nitrogen from soils was similar to $\mathrm{NO}_{3}{ }^{-}-\mathrm{N}$, and $\mathrm{NO}_{3}{ }^{-}-\mathrm{N}$ leaching loss was the main form of nitrogen leaching loss, accounting for $76-98 \%$ of total nitrogen leaching loss in fertilization treatments (Fig. 3, Table 2). However, the first leaching loss of total nitrogen from soils fed with urea (U1, U2, $\mathrm{U} 1+\mathrm{B}, \mathrm{U} 2+\mathrm{B}$ ) was much higher than that of $\mathrm{NO}_{3}{ }^{-}-\mathrm{N}$ at the same level of nitrogen fertilization (Fig. 3c). The cumulative leaching loss of total nitrogen was $15.33 \%$ higher from soils fed with U1 than from soil fed with U2, which was $29.72 \%$ higher with $\mathrm{U} 1+\mathrm{B}$ treatment than $\mathrm{U} 2+\mathrm{B}$ treatment (Table 2). The cumulative leaching loss of total nitrogen followed the decrease order as bellow: $\mathrm{U} 1>\mathrm{U} 1+\mathrm{B}>\mathrm{BCU} 1$, $\mathrm{U} 2>\mathrm{U} 2+\mathrm{B}>\mathrm{BCU} 2$, and $\mathrm{U} 1+\mathrm{B}>\mathrm{BCU} 1+\mathrm{B}$ (Table 2). In detail, the cumulative leaching loss of total nitrogen was $36.17 \%$ lower in BCU1 than in U1, and $33.55 \%$ lower in BCU1 than in $\mathrm{U} 1+\mathrm{B}$, it was also $36.5 \%$ lower in BCU2 than in U2; and $25.7 \%$ lower in BCU2 than in $\mathrm{U} 2+\mathrm{B}$ (Table 2).

Obvious difference of cumulative loss of nitrogen fertilizer during experiment for 65 days was determined in dependence on the level of nitrogen fertilization, sources of nitrogen fertilizer, and application of biochar. Amount of cumulative nitrogen loss of nitrogen fertilizer followed the decreasing order as bellow: $\mathrm{U} 1>\mathrm{U} 1+\mathrm{B}>\mathrm{BCU} 1$, $\mathrm{U} 2>\mathrm{U} 2+\mathrm{B}>\mathrm{BCU} 2$; the percentage of cumulative loss of nitrogen fertilizer in nitrogen application followed the decreasing order as bellow irrespective of the level of nitrogen fertilization: urea $(\mathrm{U} 1, \mathrm{U} 2)>$ biochar combined with urea $(\mathrm{U} 1+\mathrm{B}, \mathrm{U} 2+\mathrm{B})>$ biochar-coated urea $(\mathrm{BCU} 1$, $\mathrm{BCU} 2$ ); $\mathrm{U} 1+\mathrm{B}>\mathrm{BCU} 1+\mathrm{B}$ (Table 3). Implying that both application of biochar-coated urea and biochar combined with urea could significantly reduce the loss of nitrogen fertilizer. However, the optimal measure of controlling nitrogen loss was biochar combined with biochar coated urea. 

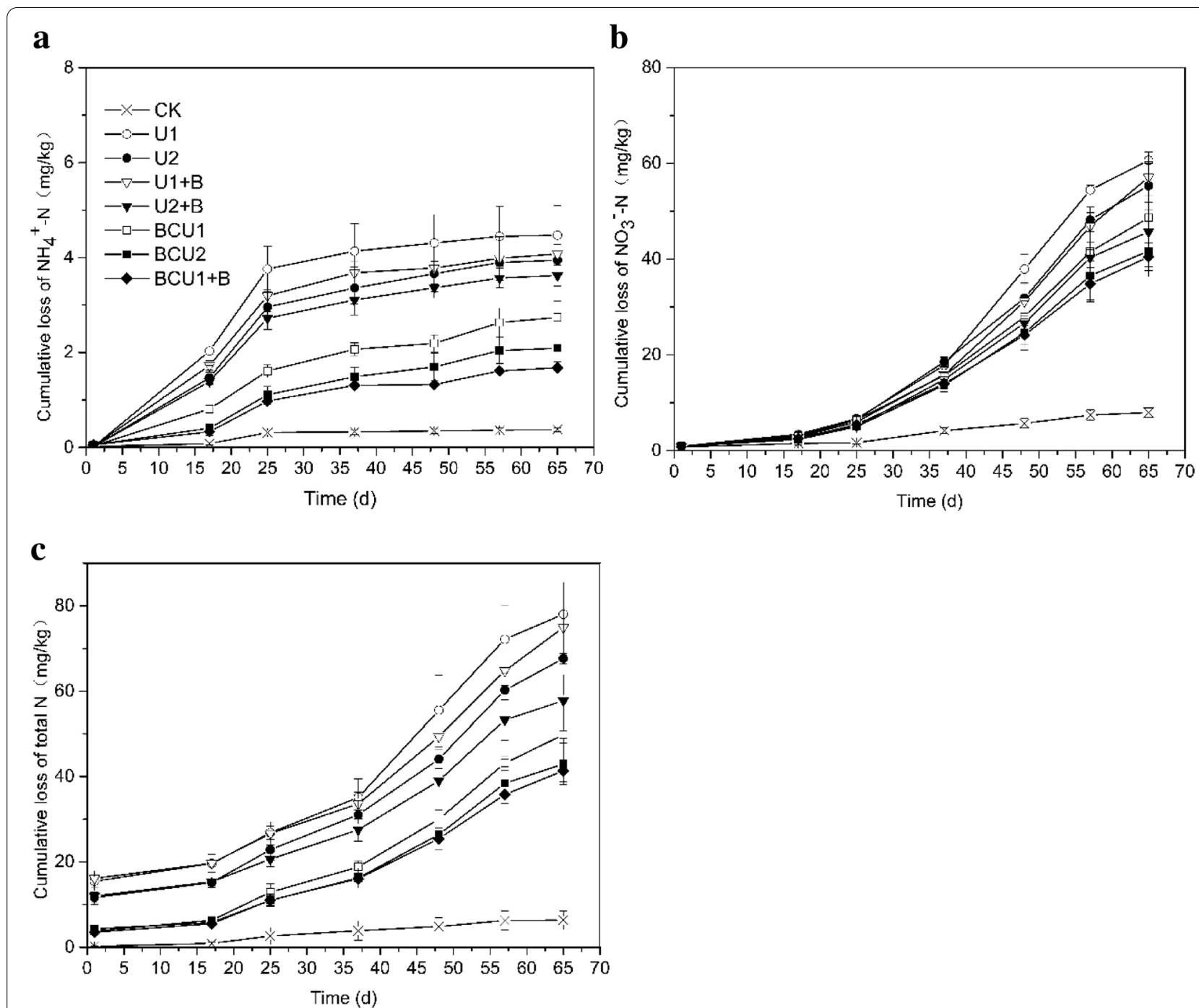

Fig. 3 Cumulative loss of nitrogen and production of $\mathrm{NH}_{4}{ }^{+}-\mathrm{N}$, and $\mathrm{NO}_{3}{ }^{-}-\mathrm{N}$ in different fertilized soils due to leaching during experiment for 65 days. a $\mathrm{NH}_{4}{ }^{+}-\mathrm{N}, \mathbf{b} \mathrm{NO}_{3}{ }^{-}-\mathrm{N}$, c total $\mathrm{N}$. CK, no fertilizer; U1, urea at $100 \% \mathrm{~N}$ rate; U2, urea at $80 \% \mathrm{~N}$ rate; $\mathrm{U} 1+\mathrm{B}$, biochar combined with urea at $100 \%$ $\mathrm{N}$ rate; $\mathrm{U} 2+\mathrm{B}$, biochar combined with urea at $80 \% \mathrm{~N}$ rate; $\mathrm{BCU1}$, biochar-coated urea at $100 \% \mathrm{~N}$ rate; $\mathrm{BCU}$, biochar-coated urea at $80 \% \mathrm{~N}$ rate; $\mathrm{BCU} 1+\mathrm{B}$, biochar combined with biochar-coated urea at $100 \% \mathrm{~N}$ rate. Error bars represent $\pm s \mathrm{~d}(n=3)$

\section{Effect of $\mathrm{BCU}$ application on soil $\mathrm{pH}$ and soil nitrogen concentrations}

The $\mathrm{pH}$ of soils collected after harvesting oilseed rape ranged from 5.89 to 6.27 , (Table 4). The greatest soil $\mathrm{pH}$ among treatments was observed in BCU1 $+\mathrm{B}$ treatment. The soil $\mathrm{pH}$ was greater in $\mathrm{CK}$ than in urea treatments (U1, U2) and in biochar-coated urea treatments (BCU1, BCU2). No obvious difference was found between $\mathrm{CK}$ and $\mathrm{U} 1+\mathrm{B}$ or $\mathrm{U} 2+\mathrm{B}$ soil $\mathrm{pH}$. However, in $\mathrm{BCU} 1+\mathrm{B}$ treatment $\mathrm{pH}$ was higher than $\mathrm{CK}$ (Table 4). Furthermore, the soil $\mathrm{pH}$ followed the decreasing order as bellow irrespective of nitrogen fertilization level: biochar combined with urea $(\mathrm{U} 1+\mathrm{B}, \mathrm{U} 2+\mathrm{B})>$ biochar-coated urea (BCU1, BCU2) > urea $(\mathrm{U} 1, \mathrm{U} 2)$ (Table 4).
The concentrations of $\mathrm{NH}_{4}{ }^{+}-\mathrm{N}, \mathrm{NO}_{3}{ }^{-}-\mathrm{N}$ and total nitrogen in soils fertilized with nitrogen were significantly higher than that in CK, which was higher in soil applied with high nitrogen levels than in soil applied with low nitrogen (Table 4). The greatest concentrations of $\mathrm{NH}_{4}{ }^{+}-\mathrm{N}$ and $\mathrm{NO}_{3}{ }^{-}-\mathrm{N}$ in soils among treatments was observed in $\mathrm{BCU} 1+\mathrm{B}$ treatment; The greatest concentrations of total nitrogen in soils among treatments was observed in $\mathrm{U} 1+\mathrm{B}$ treatment, followed by BCU1 $+\mathrm{B}$ treatment (Table 4). Furthermore, concentrations of $\mathrm{NH}_{4}{ }^{+}-\mathrm{N}$ and $\mathrm{NO}_{3}{ }^{-}-\mathrm{N}$ in soils followed the decreasing order: $\mathrm{U} 1+\mathrm{B}$, BCU1 > U1; U2 + B, BCU2 > U2. However, concentrations of total nitrogen in soils followed the decreasing 
order as bellow: $\mathrm{U} 1+\mathrm{B}>\mathrm{BCU} 1, \mathrm{U} 1 ; \mathrm{U} 2+\mathrm{B}>\mathrm{BCU} 2$, U2 (Table 4).

\section{Effect of BCU application on nitrogen uptake and nitrogen use efficiency}

The nitrogen concentration and nitrogen uptake of oilseed rape in CK was lowest among all treatments (Table 5). The nitrogen concentration and nitrogen uptake of oilseed rape grown in soils fertilized with nitrogen were significantly higher than that in CK (Table 5). The concentration of nitrogen in oilseed rape followed the decreasing order as bellow: biochar-coated urea (BCU1, BCU2) > biochar combined with urea $(\mathrm{U} 1+\mathrm{B}$, $\mathrm{U} 2+\mathrm{B})>$ urea (U1, U2); no obvious difference between $\mathrm{BCU} 1+\mathrm{B}$ and $\mathrm{U} 1+\mathrm{B}$. The uptake of nitrogen in oilseed rape under the same level of nitrogen fertilization followed the decreasing order as bellow: biochar-coated urea (BCU1, BCU2) $>$ biochar combined with urea $(\mathrm{U} 1+\mathrm{B}, \quad \mathrm{U} 2+\mathrm{B})>$ urea $\quad(\mathrm{U} 1, \quad \mathrm{U} 2) ; \quad \mathrm{BCU} 1+\mathrm{B}>\mathrm{U} 1+\mathrm{B}$ (Table 5).

The NUE followed the decreasing order as bellow irrespective of nitrogen fertilization level: biochar-coated urea (BCU1, BCU2) $>$ biochar combined with urea $(\mathrm{U} 1+\mathrm{B}, \quad \mathrm{U} 2+\mathrm{B})>$ urea $(\mathrm{U} 1, \quad \mathrm{U} 2) ; \mathrm{BCU} 1+\mathrm{B}>\mathrm{U} 1+\mathrm{B}$ (Table 5). Thus, it could be seen that application of biochar-coated urea could significantly increase NUE compared to urea application.

\section{Effect of BCU application on oilseed rape growth}

Biomass of oilseed rape was higher with high nitrogen fertilization level than low nitrogen level (Table 5). Furthermore, biomass of oilseed rape tended to follow the decreasing order as bellow: biochar-coated urea $(\mathrm{BCU} 1, \mathrm{BCU} 2)>$ biochar combined with urea $(\mathrm{U} 1+\mathrm{B}, \mathrm{U} 2+\mathrm{B})>$ urea $(\mathrm{U} 1, \mathrm{U} 2)$, under high nitrogen fertilization level; biochar-coated urea (BCU1, BCU2) $>$ biochar combined with urea $(\mathrm{U} 1+\mathrm{B}, \mathrm{U} 2+\mathrm{B})$, urea $(\mathrm{U} 1, \mathrm{U} 2)$, under low nitrogen fertilization level; $\mathrm{BCU} 1+\mathrm{B}>\mathrm{U} 1+\mathrm{B}$ (Table 5); but these differences were not significant $(p<0.05)$. Moreover, biomass of oilseed rape was higher in BCU1 treatment than U1 treatment (Table 5), implying that a $20 \%$ reduction in nitrogen application would not reduce biomass if urea was replaced with biochar-coated urea. Biomass of oilseed rape was significantly lower in $\mathrm{U} 2+\mathrm{B}$ treatment than in U1 treatment (Table 5). It could be seen that a $20 \%$ reduction in nitrogen application would reduce biomass even if urea was combined with biochar.

\section{Discussion}

Effects and mechanisms of BCU application on controlling loss of nitrogen

The leaching, volatilization as $\mathrm{NH}_{3}-\mathrm{N}$ and nitrous oxide, and runoff are main pathways of nitrogen loss in soil fertilized with nitrogen [31]. The leaching loss of total nitrogen, $\mathrm{NH}_{4}{ }^{+}-\mathrm{N}$ and $\mathrm{NO}_{3}{ }^{-}-\mathrm{N}$, and volatilization loss as $\mathrm{NH}_{3}-\mathrm{N}$ were considered in the present culture experiment, because nitrous oxide produced by denitrification was reported to account for only a small proportion of nitrogen fertilization (about 1\%) [32], and no runoff during the present culture experiment. The results of the present experiment demonstrated that total loss of nitrogen via leaching, and $\mathrm{NH}_{3}-\mathrm{N}$ volatilization accounted for $20.99-40.76 \%$ of nitrogen fertilization (Table 3). The total loss of nitrogen via leaching accounted for $72.42-83.07 \%$, $3.42-5.92 \%$, and $4.95-15.71 \%$ distributed in $\mathrm{NO}_{3}{ }^{-}-\mathrm{N}$,

Table 3 Cumulative loss of fertilizer nitrogen in soil and percentage of cumulative loss of fertilizer nitrogen in nitrogen application after the $65 \mathrm{~d}$ experiment

\begin{tabular}{|c|c|c|c|c|c|c|c|}
\hline \multirow{2}{*}{$\begin{array}{l}\text { Fertilization } \\
\text { treatments }\end{array}$} & \multirow{2}{*}{$\begin{array}{l}\text { Amount of } \mathrm{N} \\
\text { fertilization }(\mathrm{mg} / \mathrm{kg})\end{array}$} & \multicolumn{3}{|c|}{ Leaching loss of fertilizer-N (mg/kg) } & \multirow{2}{*}{$\begin{array}{l}\mathrm{NH}_{3} \text { volatilization } \\
\text { of fertilizer- } \mathrm{N}(\mathrm{mg} / \mathrm{kg})\end{array}$} & \multirow{2}{*}{$\begin{array}{l}\text { Total loss } \\
\text { of fertilizer-N (mg/ } \\
\text { kg) }\end{array}$} & \multirow[t]{2}{*}{ Percentage (\%) } \\
\hline & & Total N & $\mathrm{NH}_{4}{ }^{+}-\mathrm{N}$ & $\mathrm{NO}_{3}{ }^{-}-\mathrm{N}$ & & & \\
\hline U1 & 200 & 71.69 & 4.10 & 52.69 & 4.87 & 76.56 & 38.28 \\
\hline U2 & 160 & 61.31 & 3.57 & 47.39 & 3.91 & 65.22 & 40.76 \\
\hline $\mathrm{U} 1+\mathrm{B}$ & 200 & 68.61 & 3.70 & 49.18 & 3.17 & 71.78 & 35.89 \\
\hline $\mathrm{U} 2+\mathrm{B}$ & 160 & 51.44 & 3.25 & 37.76 & 2.65 & 54.08 & 33.80 \\
\hline BCU1 & 200 & 43.47 & 2.37 & 40.68 & 8.24 & 51.70 & 25.85 \\
\hline BCU2 & 160 & 36.60 & 1.7 & 33.74 & 6.47 & 43.08 & 26.92 \\
\hline$B C U 1+B$ & 200 & 35.01 & 1.30 & 32.52 & 6.97 & 41.98 & 20.99 \\
\hline
\end{tabular}

Amount of $\mathrm{N}$ fertilization: only nitrogen as application of urea or biochar-coated urea is considered due to very little nitrogen in biochar

Loss of $\mathrm{N}$ fertilizer $=$ Fertilization treatment-CK

Total loss of fertilizer- $\mathrm{N}=$ Leaching loss of total $\mathrm{N}+\mathrm{NH}_{3}$ volatilization loss

$\%$ - Percentage of loss of fertilizer nitrogen in nitrogen application

$\mathrm{U} 1$, urea at $100 \% \mathrm{~N}$ rate; $\mathrm{U} 2$, urea at $80 \% \mathrm{~N}$ rate; $\mathrm{U} 1+\mathrm{B}$, biochar combined with urea at $100 \% \mathrm{~N}$ rate; $\mathrm{U} 2+\mathrm{B}$, biochar combined with urea at $80 \% \mathrm{~N}$ rate; $\mathrm{BCU}$ 1, biocharcoated urea at $100 \% \mathrm{~N}$ rate; $\mathrm{BCU} 2$, biochar-coated urea at $80 \% \mathrm{~N}$ rate; $\mathrm{BCU} 1+\mathrm{B}$, biochar combined with biochar-coated urea at $100 \% \mathrm{~N}$ rate 
Table 4 Concentration of nitrogen $(\mathrm{mg} / \mathrm{kg})$ and $\mathrm{pH}$ in different fertilized soils collected after harvesting oil rapeseed

\begin{tabular}{|c|c|c|c|c|}
\hline Treatments & $\mathrm{pH}$ & $\mathrm{NH}_{4}^{+}-\mathrm{N}(\mathrm{mg} / \mathrm{kg})$ & $\mathrm{NO}_{3}{ }^{-}-\mathrm{N}(\mathrm{mg} / \mathrm{kg})$ & Total nitrogen $(\mathrm{mg} / \mathrm{kg})$ \\
\hline CK & $6.17 \pm 0.20 \mathrm{ab}$ & $7.34 \pm 1.07 e$ & $22.09 \pm 0.848 c$ & $254.06 \pm 9.38 d$ \\
\hline U1 & $5.95 \pm 0.10 b c$ & $14.42 \pm 1.75 \mathrm{bcd}$ & $58.99 \pm 3.22 \mathrm{a}$ & $294.42 \pm 16.81 d$ \\
\hline U2 & $5.89 \pm 0.04 c$ & $11.72 \pm 1.57 \mathrm{~d}$ & $40.46 \pm 4.15 b$ & $277.01 \pm 26.99 d$ \\
\hline $\mathrm{U} 1+\mathrm{B}$ & $6.19 \pm 0.13 a b$ & $17.45 \pm 3.47 a b$ & $62.29 \pm 4.13 a$ & $485.61 \pm 72.93 a$ \\
\hline $\mathrm{U} 2+\mathrm{B}$ & $6.18 \pm 0.15 a b$ & $12.48 \pm 2.11 \mathrm{~cd}$ & $44.12 \pm 7.11 b$ & $384.18 \pm 77.35 b c$ \\
\hline BCU1 & $6.10 \pm 0.10 \mathrm{abc}$ & $15.68 \pm 2.41 \mathrm{abc}$ & $63.41 \pm 3.44 a$ & $321.87 \pm 16.76 c$ \\
\hline BCU2 & $6.03 \pm 0.15 a b c$ & $12.59 \pm 1.61 \mathrm{~cd}$ & $45.19 \pm 2.37 b$ & $280.20 \pm 25.85 d$ \\
\hline$B C U 1+B$ & $6.27 \pm 0.02 \mathrm{a}$ & $18.99 \pm 1.03 a$ & $64.79 \pm 8.11 a$ & $441.68 \pm 26.83 a b$ \\
\hline
\end{tabular}

$\mathrm{CK}$, no fertilizer; $\mathrm{U} 1$, urea at $100 \% \mathrm{~N}$ rate; $\mathrm{U} 2$, urea at $80 \% \mathrm{~N}$ rate; $\mathrm{U} 1+\mathrm{B}$, biochar combined with urea at $100 \% \mathrm{~N}$ rate; $\mathrm{U} 2+\mathrm{B}$, biochar combined with urea at $80 \% \mathrm{~N}$ rate; $\mathrm{BCU1}$, biochar-coated urea at $100 \% \mathrm{~N}$ rate; $\mathrm{BCU} 2$, biochar-coated urea at $80 \% \mathrm{~N}$ rate; $\mathrm{BCU} 1+\mathrm{B}$, biochar combined with biochar-coated urea at $100 \% \mathrm{~N}$ rate Different letters in the same column indicate a significant difference at the $5 \%$ level according to the LSD test

$\mathrm{NH}_{4}{ }^{+}-\mathrm{N}$, and $\mathrm{NH}_{3}-\mathrm{N}$ respectively (Figs. 2, 3, Table 2). It followed that leaching loss of $\mathrm{NO}_{3}^{-}-\mathrm{N}$ was predominately pathway of nitrogen loss in the present culture experiment.

The results of the present experiment also demonstrated that total loss of nitrogen via leaching, and $\mathrm{NH}_{3}-\mathrm{N}$ volatilization accounted for $25.85-26.92 \%$ of applied nitrogen as biochar-coated urea (BCU1, BCU2) (Table 3). When biochar-coated urea was used as nitrogen fertilizer, the total loss of nitrogen accounted for 82.69-83.07\%, 4.17-4.67\%, and $14.38-15.27 \%$ distributed in $\mathrm{NO}_{3}{ }^{-}-\mathrm{N}, \mathrm{NH}_{4}{ }^{+}-\mathrm{N}$, and $\mathrm{NH}_{3}-\mathrm{N}$ respectively (Figs. 2, 3, Table 2). It can be seen that leaching loss of $\mathrm{NO}_{3}{ }^{-}-\mathrm{N}$ was the predominant pathway of nitrogen loss when biochar-coated urea was used as nitrogen fertilizer. Similar results were also obtained from the investigation of Wang et al, who observed that the nitrogen loss via leaching was higher than that via $\mathrm{NH}_{3}-\mathrm{N}$ volatilization, and leaching loss of $\mathrm{NO}_{3}{ }^{-}-\mathrm{N}$ was accounted for 51.695.7\% of total nitrogen leached when biochar-coated urea was used as nitrogen fertilizer [29].
The results of the present culture experiment showed that application of coated urea could significantly reduce nitrogen fertilizer loss compared with application of urea alone, because the loss of nitrogen in soil fed with BCU was about $30 \%$ lower than that in soil fed with urea (Figs. 2, 3, Table 2); the loss of nitrogen fertilizer as biochar-coated urea (BCU1, BCU2) was 32.48-33.95\% lower than that as urea (U1, U2). The main pathway of reducing loss of nitrogen fertilizer as $\mathrm{BCU}$ could contribute to reduce nitrogen leaching loss rather than loss of volatilization via $\mathrm{NH}_{3}-\mathrm{N}$, because volatilization loss via $\mathrm{NH}_{3}-\mathrm{N}$ was greater in soils fed with biochar-coated urea (BCU1, BCU2) than in soils fed with urea (U1, U2) (Fig. 2). The $\mathrm{NH}_{3}-\mathrm{N}$ volatilization loss of nitrogen fertilizer as biochar-coated urea was greater than that as urea under the same nitrogen fertilization level (Table 3). The mechanism of $\mathrm{BCU}$ application for reducing the leaching loss of nitrogen mainly included the following two aspects. Firstly, BCU used in this present experiment had good slow-release properties [15]. Slow-release fertilizer

Table 5 Concentration of nitrogen in oilseed rape, amount of oilseed rape nitrogen uptake, nitrogen utilization efficiency of fertilized nitrogen, and biomass of oilseed rape under different fertilized treatments

\begin{tabular}{lllc}
\hline Treatment & $\begin{array}{l}\text { Nitrogen in oilseed rape } \\
\text { concentration } \mathbf{( m g / k g )}\end{array}$ & $\begin{array}{l}\text { Amount of oilseed rape nitrogen } \\
\text { uptake (mg/pot) }\end{array}$ & $\begin{array}{l}\text { Biomass of oilseed } \\
\text { rape (g/pot) }\end{array}$ \\
\hline CK & $58.77 \pm 2.44 \mathrm{c}$ & $78.54 \pm 23.79 \mathrm{c}$ & $\begin{array}{l}\text { Nitrogen utilization } \\
\text { efficiency of fertilized } \\
\text { nitrogen (\%) }\end{array}$ \\
U1 & $65.03 \pm 0.86 \mathrm{bc}$ & $200.65 \pm 36.91 \mathrm{~b}$ & $1.33 \pm 0.36 \mathrm{c}$ \\
U2 & $64.40 \pm 1.54 \mathrm{bc}$ & $176.42 \pm 46.77 \mathrm{~b}$ & $3.09 \pm 0.57 \mathrm{ab}$ \\
U1+B & $72.07 \pm 5.06 \mathrm{a}$ & $244.33 \pm 47.79 \mathrm{ab}$ & $2.73 \pm 0.66 \mathrm{~b}$ \\
U2+B & $70.97 \pm 5.82 \mathrm{ab}$ & $188.83 \pm 36.19 \mathrm{~b}$ & $3.41 \pm 0.80 \mathrm{ab}$ \\
BCU1 & $72.77 \pm 3.54 \mathrm{a}$ & $283.57 \pm 48.10 \mathrm{a}$ & $2.65 \pm 0.34 \mathrm{~b}$ \\
BCU2 & $70.63 \pm 1.01 \mathrm{ab}$ & $238.56 \pm 57.87 \mathrm{ab}$ & $3.89 \pm 0.58 \mathrm{a}$ \\
BCU1+B & $71.77 \pm 4.39 \mathrm{a}$ & $280.98 \pm 24.45 \mathrm{a}$ & $3.38 \pm 0.86 \mathrm{ab}$ \\
\hline
\end{tabular}

$\mathrm{CK}$, no fertilizer; $\mathrm{U} 1$, urea at $100 \% \mathrm{~N}$ rate; $\mathrm{U} 2$, urea at $80 \% \mathrm{~N}$ rate; $\mathrm{U} 1+\mathrm{B}$, biochar combined with urea at $100 \% \mathrm{~N}$ rate; $\mathrm{U} 2+\mathrm{B}$, biochar combined with urea at $80 \% \mathrm{~N}$ rate; $\mathrm{BCU} 1$, biochar-coated urea at $100 \% \mathrm{~N}$ rate; $\mathrm{BCU} 2$, biochar-coated urea at $80 \% \mathrm{~N}$ rate; $\mathrm{BCU} 1+\mathrm{B}$, biochar combined with biochar-coated urea at $100 \% \mathrm{~N}$ rate 
was reported to delay the release of nitrogen fertilizer, and to extend the time for crops to absorb and use fertilizer nitrogen, ultimately to decrease leaching loss of nitrogen [33]. The present experiment observed that the cumulative leaching amount of total nitrogen, $\mathrm{NH}_{4}{ }^{+}-\mathrm{N}$ and $\mathrm{NO}_{3}{ }^{-}-\mathrm{N}$ was lower in soils fed with $\mathrm{BCU}$ than in soils fed with urea, especially at the first leaching event (Fig. 3). This was because urea inside BCU was partially dissolved due to the barrier effect of the coated materials (biochar). Secondly, biochar with large specific surface area, and negative surface functional groups could increase soil water holding capacity and soil microorganism, nitrification and nitrogen adsorption (such as $\mathrm{NH}_{4}{ }^{+}-\mathrm{N}$ and $\mathrm{NO}_{3}{ }^{-}-\mathrm{N}$ ), ultimately to reduce nitrogen losses $[18,32,34]$.

The present results demonstrated that the cumulative leaching loss of total nitrogen, $\mathrm{NH}_{4}{ }^{+}-\mathrm{N}$ and $\mathrm{NO}_{3}{ }^{-}-\mathrm{N}$ were lower in soils fed with biochar combined with urea $(\mathrm{U} 1+\mathrm{B}, \mathrm{U} 2+\mathrm{B})$ than in soils fed with urea $(\mathrm{U} 1, \mathrm{U} 2)$ at the same nitrogen fertilization level (Table 2). However, the dynamics of leaching of total nitrogen, $\mathrm{NH}_{4}{ }^{+}-\mathrm{N}$ and $\mathrm{NO}_{3}{ }^{-}-\mathrm{N}$ in soils fed with urea combined with biochar were similar to those in soils fed urea (Fig. 3). Direct biochar application was found to reduce nitrogen loss from leaching, due to its adsorption ability to achieve nitrogen retention. However, the direct application of biochar did not achieve slow release of nitrogen fertilizer.

In the present study, compared with individual application of urea, urea combined with biochar significantly reduced loss of $\mathrm{NH}_{3}$ volatilization, but biochar-coated urea significantly increased loss of $\mathrm{NH}_{3}$ volatilization (Fig. 2). The ammonia volatilization loss of nitrogen fertilizer was reported to mainly relate to nitrogen release of fertilizer, residue of nitrogen in soil, ammonia adsorption/fixation, nitrification, and soil pH [29, 34, 35]. Zheng et al. observed that the ammonia volatilization was more likely to occur when soil $\mathrm{pH}$ was above 8 [11]. The $\mathrm{pH}$ values were slightly greater in soils fed with biocharcoated urea (BCU1, BCU2) than in soils fed with urea (U1, U2), which was within the range of acidity (Table 4). Therefore, the increase of bulk soil pH due to BCU application could not be the main factor for the increase of ammonia volatilization observed. High ammonia volatilization in soils fed with BCU compared to urea could be contributed to high soil $\mathrm{NH}_{4}{ }^{+}-\mathrm{N}$ concentration, because concentrations of $\mathrm{NH}_{4}^{+}-\mathrm{N}$ were greater in soils fed with $\mathrm{BCU}$ than in soils fed with urea under the same nitrogen fertilization (Table 4); application of BCU prolonged the time of ammonia volatilization (Fig. 2). Moreover, coated biochar induced alkaline microenvironment outside urea could also contribute to ammonia volatilization. Puga et al. have observed that biochar as coating material increased ammonia volatilization of nitrogen fertilizer, while application of biochar combined urea reduced ammonia volatilization [28]. However, reduction rate of nitrogen fertilization as BCU by $20 \%$ (BCU2) was observed to reduce ammonia volatilization loss. In conclusion, although the application of $\mathrm{BCU}$ increased ammonia volatilization, it significantly reduced nitrogen leaching, and ultimately reduced total nitrogen loss of nitrogen fertilizer.

Total loss of nitrogen fertilizer followed the decreasing order as bellow: $\mathrm{BCU} 1+\mathrm{B}>\mathrm{BCU} 1>\mathrm{U} 1+\mathrm{B}$ (Table 3 ). Implying that application of biochar combined with $\mathrm{BCU}$ was more conducive to reduce nitrogen fertilizer loss. However, additional biochar application will have to add additional cost. Therefore, application of biochar-coated urea could be a promising alternative measure for reducing loss of nitrogen. However, further investigations were required to validate dosage-effect relationship of $\mathrm{BCU}$ on the loss of nitrogen at the field scale.

\section{Effects and mechanisms of BCU application on NUE}

Coated fertilizer has incomparable virtues than other chemical fertilizers in improving NUE, reducing environmental pollution, and saving labour, because it could most likely match the nutrient release rate to crop's demand by coating materials design among controlled slow release fertilizers [36, 37]. The present results showed that the BCU used in the present study could effectively improve the NUE of fertilized nitrogen, because the NUE of biochar coated urea was significantly greater than that of urea irrespective of nitrogen fertilization level (Table 5). The mechanisms for BCU to improve the NUE of fertilized nitrogen mainly included the following aspects. Firstly, application of BCU reduced nitrogen loss due to its good slow-release and adsorption/ retention properties of biochar as coating material. Puga et al. observed that the improvement of NUE for biochar-based fertilizers was related to the gradual release of nitrogen and the reduction of nitrogen leaching loss [38]. The BCU used in the present experiment had good slow release properties [15], and the total nitrogen loss in soil fed with BCU was about $30 \%$ lower compared with urea (Fig. 2, Table 2). Secondly, the application of BCU increased soil nitrogen residue, crop nitrogen uptake. The present results indicated that the concentrations of total nitrogen, $\mathrm{NH}_{4}{ }^{+}-\mathrm{N}$ and $\mathrm{NO}_{3}{ }^{-}-\mathrm{N}$ of soils fed with $\mathrm{BCU}$ were greater than that of soils fed with urea under the same level of nitrogen fertilization (Table 4). Zheng et al. also observed that application of biochar enhanced fixation of nitrogen in soils [11]. Thirdly, the application of BCU increased crop nitrogen uptake. The present results showed that the nitrogen concentration and nitrogen uptake of oilseed rape was greater in BCU treatments than in urea treatments (Table 5). Liu et al. observed that 
application of maize stover biochar improved NUE of urea and enhanced soil $\mathrm{N}$ availability to Ryegrass (Lolium perenne L.) [35].

The present results showed that the NUE for $\mathrm{BCU} 1+\mathrm{B}$ and $\mathrm{BCU} 1$ was greater than that for $\mathrm{U} 1+\mathrm{B}$, but no difference of NUE between BCU1 + B and BCU1 was observed (Table 5). Implying that both application of biochar combined with urea, and biochar coated urea can improve NUE, but application of biochar combined with BCU could not result in further improvement of NUE compared with application of BCU. It could be seen that biochar combined with BCU can control loss of nitrogen, but can't improve NUE compared to the application of BCU. Additional biochar applications require additional costs. Therefore, application of BCU could be a promising alternative measure for improving NUE of nitrogen fertilizer. However further investigations are required to validate optimization of $\mathrm{BCU}$ fertilization levels at the field scale.

Moreover, reduction rate of nitrogen fertilization as BCU (BCU2) by $20 \%$ was not observed to decrease the biomass of oilseed rape. The biomass of oilseed rape was $10 \%$ higher with $\mathrm{BCU} 2$ treatments than $\mathrm{U} 1$ treatment, which was equivalent to $\mathrm{U} 1+\mathrm{B}$ (Table 5). Therefore, application of BCU could be a promising controlled release nitrogen fertilizer for reducing loss of nitrogen and improving NUE without negative impact on plant yield.

\section{Conclusions}

The present study demonstrated that nitrogen fertilization as BCU could not only significantly reduce nitrogen loss but effectively improve NUE compared to urea. However, results showed that although volatilization loss of $\mathrm{BCU}$ was higher due to $\mathrm{BCU}$-induced residue of $\mathrm{NH}_{4}{ }^{+}-\mathrm{N}$ nitrogen in soils, the total nitrogen reduction of $\mathrm{BCU}$ was lower. This was mainly because the application of $\mathrm{BCU}$ largely reduced the nitrogen leaching loss. The application of BCU significantly increased NUE of $\mathrm{BCU}$ compared with urea, which could contribute to the application of $\mathrm{BCU}$-induced reduction of nitrogen fertilizer loss, increasing uptake of nitrogen in plant, and residue of nitrogen in soils. The reduction rate of nitrogen fertilization as BCU (BCU2) by $20 \%$ was not observed to decrease the biomass of oilseed rape. $\mathrm{BCU}$ combined with biochar was observed to further reduce the loss of nitrogen compared with BCU, but NUE was a little lower. Also, the additional biochar application inevitably increased the cost of fertilization. The application of BCU was more convenient to operate and could avoid the problems of biochar powder dispersion, compared with directly applying biochar into the soil. Therefore, the application of BCU could be a promising control release nitrogen fertilizer for reducing nitrogen loss and improving NUE without any negative impact on plant yield. However, further investigations are required to validate the dosage-effect relationship of $\mathrm{BCU}$ on the loss of nitrogen, NUE, and crop yield at the field scale.

\section{Supplementary information}

The online version contains supplementary material available at https://doi. org/10.1186/s40538-020-00205-4.

Additional file 1:Fig. S1. SEM images of biochar used for biochar-coated urea. Fig. S2. FTIR spectra of biochar used for biochar-coated urea. The band at $1570 \mathrm{~cm}^{-1}$ correspond to keto $\mathrm{C}=\mathrm{O}$ stretching vibrations in esters or $\mathrm{C}=\mathrm{C}$ stretching vibrations in alkene and aromatic compounds; The band at $1030 \mathrm{~cm}^{-1}$ correspond to $\mathrm{C}-\mathrm{O}$ stretching vibrations in lignin derivatives or alcohols and phenols". Fig. S3. ${ }^{13} \mathrm{C}$ NMR spectra of biochar used for biochar-coated urea. Resonance region at 110-150 ppm indicated aromatic carbon. Fig. S4. Schematic plot of ammonia volatilization collection.

\section{Abbreviations}

NUE: Nitrogen use efficiency; BCU: Biochar-coated urea; Bio-MUC: Biocharmineral urea composite.

\section{Acknowledgements}

Not applicable.

\section{Authors' contributions}

YJ and ZH designed the experiments and wrote the paper. YJ performed the experiments. YJ and WQ analyzed the data. YB provided guidance during experimental work. All authors read and approved the final manuscript.

\section{Funding}

This project was funded by the National Key Research and Development Project (No. 2016YFD0800100-04), Blue Sky Zhenggao (Beijing) Agricultural Science and Technology Co., LTD, and Shenwu technology group corp Co., LTD.

Availability of data and materials

All data generated or analysed during this study are included in this published article (and its Additional file 1).

Ethics approval and consent to participate

Not applicable.

\section{Consent for publication}

Not applicable.

\section{Competing interests}

The authors declare that they have no competing interests.

\section{Author details}

${ }^{1}$ College of Resources and Environment, University of Chinese Academy of Sciences, Beijing 101408, China. ${ }^{2}$ Sino- Danish Center for Education and Research, Beijing 100190, China. ${ }^{3}$ Research Center for Eco-Environmental Sciences, Chinese Academy of Sciences, Beijing 100085, China. ${ }^{4}$ Blue Sky Zhenggao (Beijing) Agricultural Science and Technology Co., LTD, Beijing, China. ${ }^{5}$ Shenwu Technology Group Corp Co., LTD, Beijing, China.

Received: 1 October 2020 Accepted: 27 December 2020 Published online: 08 January 2021 


\section{References}

1. Jia X, Shao L, Liu P, Zhao B, Gu L, Dong S, Bing SH, Zhang J, Zhao B. Effect of different nitrogen and irrigation treatments on yield and nitrate leaching of summer maize (Zea mays L.) under lysimeter conditions. Agr Water Manage. 2014;137:92-103.

2. Naz MY, Sulaiman SA. Slow release coating remedy for nitrogen loss from conventional urea: a review. J Control Release. 2016;225:109-20.

3. Cao H, Ning L, Xun M, Feng F, Li P, Yue S, Song J, Zhang W, Yang H. Biochar can increase nitrogen use efficiency of Malus hupehensis by modulating nitrate reduction of soil and root. Appl Soil Ecol. 2019;135:25-32.

4. Jiang Y, Sun Y, Pan J, Qi S, Chen Q, Tong D. Nitrogen removal and $\mathrm{N}_{2} \mathrm{O}$ emission in subsurface wastewater infiltration systems with/without intermittent aeration under different organic loading rates. Bioresource Technol. 2017;244:8-14.

5. Sun C, Chen L, Zhai L, Liu H, Wang K, Jiao C, Shen Z. National assessment of nitrogen fertilizers fate and related environmental impacts of multiple pathways in China. J Clean Prod. 2020;277:123519.

6. Wang Y, Lu Y. Evaluating the potential health and economic effects of nitrogen fertilizer application in grain production systems of China.J Clean Prod. 2020;264:121635.

7. Cui Z, Zhang H, Chen X, Zhang C, Ma W, Huang C, et al. Pursuing sustainable productivity with millions of smallholder farmers. Nature. 2018;555(7696):363-6.

8. Zhang X, Davidson EA, Mauzerall DL, Searchinger TD, Dumas P, Shen Y. Managing nitrogen for sustainable development. Nature. 2015:528(7580):51-9.

9. Lehmann J, Rillig MC, Thies J, Masiello CA, Hockaday WC, Crowley D. Biochar effects on soil biota-a review. Soil Biol Biochem. 2011:43:1812-36.

10. Mandal S, Donner E, Vasileiadis S, Skinner W, Smith E, Lombi E. The effect of biochar feedstock, pyrolysis temperature, and application rate on the reduction of ammonia volatilisation from biochar-amended soil. Sci Total Environ. 2018:627:942-50.

11. Zheng H, Wang Z, Deng X, Herbert S, Xing B. Impacts of adding biochar on nitrogen retention and bioavailability in agricultural soil. Geoderma. 2013;206:32-9.

12. Beck DA, Johnson GR, Spolek GA. Amending greenroof soil with biochar to affect runoff water quantity and quality. Environ Pollut. 2011;159:2111-8

13. Laird D, Fleming P, Wang B, Horton R, Karlen D. Biochar impact on nutrient leaching from a Midwestern agricultural soil. Geoderma. 2010;158:436-42.

14. Zhang P, Sun H, Yu L, Sun T. Adsorption and catalytic hydrolysis of carbaryl and atrazine on pig manure-derived biochars: impact of structural properties of biochars. J Hazard Mater. 2013;244-245:217-24.

15. Jia Y, Hu Z, Mu J, Zhang W, Xie Z, Wang G. Preparation of biochar as a coating material for biochar-coated urea. Sci Total Environ. 2020;731:139063.

16. Abbruzzini TF, Davies CA, Toledo FH, Cerri CEP. Dynamic biochar effects on nitrogen use efficiency, crop yield and soil nitrous oxide emissions during a tropical wheat-growing season. J Environ Manage. 2019;252:109638.

17. Ding Y, Liu Y, Liu S, Huang X, LI Z, Tan X, Zeng G, Zhou L. Potential benefits of biochar in agricultural soils: a review. Pedosphere. 2017; 27: 645-661.

18. Xu N, Tan G, Wang H, Gai X. Effect of biochar additions to soil on nitrogen leaching, microbial biomass and bacterial community structure. Eur J Soil Biol. 2016;74:1-8

19. Yao Y, Gao B, Zhang M, Inyang M, Zimmerman AR. Effect of biochar amendment on sorption and leaching of nitrate, ammonium, and phosphate in a sandy soil. Chemosphere. 2012;89:1467-71.

20. Schofield HK, Pettitt TR, Tappin AD, Rollinson GK, Fitzsimons MF. Biochar incorporation increased nitrogen and carbon retention in a wastederived soil. Sci Total Environ. 2019;690:1228-36.
21. Zhang Q, Song Y, Wu Z, Yan X, Gunina A, Kuzyakov Y, Xiong Z. Effects of six-year biochar amendment on soil aggregation, crop growth, and nitrogen and phosphorus use efficiencies in a rice-wheat rotation. J Clean Prod. 2020;242:118435.

22. Kim P, Hensley D, Labbé N. Nutrient release from switchgrass-derived biochar pellets embedded with fertilizers. Geoderma. 2014;232-234:341-51.

23. Clare A, Barnes A, McDonagh J, Shackley S. From rhetoric to reality: farmer perspectives on the economic potential of biochar in China. Int J Agr Sustain. 2014:12:440-58.

24. El Sharkawi HM, Tojo S, Chosa T, Malhat FM, Youssef AM. Biochar-ammonium phosphate as an uncoated-slow release fertilizer in sandy soil. Biomass Bioenerg. 2018;117:154-60.

25. Shi W, Ju Y, Bian R, Li L, Joseph S, Mitchell DRG, Munroe P, Taherymoosavi S, Pan G. Biochar bound urea boosts plant growth and reduces nitrogen leaching. Sci Total Environ. 2020;701:134424.

26. Zhou Z, Gao T, Zhu Q, Yan T, Li D, Xue J, Wu Y. Increases in bacterial community network complexity induced by biochar-based fertilizer amendments to karst calcareous soil. Geoderma. 2019:337:691-700.

27. Chen S, Yang M, Ba C, Yu S, Jiang Y, Zou H, Zhang Y. Preparation and characterization of slow-release fertilizer encapsulated by biochar-based waterborne copolymers. Sci Total Environ. 2018;615:431-7.

28. Puga AP, Queiroz MCDA, Ligo MAV, Carvalho CS, Pires AMM, Marcatto JDOS, Andrade CAD. Nitrogen availability and ammonia volatilization in biochar-based fertilizers. Arch Agron Soil Sci. 2019; 1-13.

29. Wang H, Hu Z, Zhu X, Zhou G. A comparative study of nitrogen loss after application of biochar coated urea and common urea in vegetable soil at chaihe catchment of Dianchi Lake. Agricultural Sci Technol. 2015;16(12):2688-92

30. Hu Z, Wang H, Zhu X, Zhu C, Liu X, Zhou G. Formula and film-coating preparation method for biological carbon coated urea. China. 2014;201410286966:6

31. Wang S, Feng X, Wang Y, Zheng Z, Li T, He S, Zhang X, Yu H, Huang H, Liu T, Memon SUR, Lin C. Characteristics of nitrogen loss in sloping farmland with purple soil in Southwestern China during maize (Zea mays L.) growth stages. CATENA. 2019;182:104169.

32. Ding $H$, Cai $G$, Wang $Y$, Chen $D$. Nitrification -denitrification losses of nitrogen fertilizer and $\mathrm{N}_{2} \mathrm{O}$ emission from maize-chao soil system in North China plain. Scientia Agricultura Sinica. 2001;34(4):416-21.

33. Zhang W, Liang Z, He X, Wang X, Shi X, Zou C, Chen X. The effects of controlled release urea on maize productivity and reactive nitrogen losses: a meta-analysis. Environ Pollut. 2019;246:559-65.

34. Sun H, Lu H, Chu L, Shao H, Shi W. Biochar applied with appropriate rates can reduce $\mathrm{N}$ leaching, keep $\mathrm{N}$ retention and not increase $\mathrm{NH}_{3}$ volatilization in a coastal saline soil. Sci Total Environ. 2017;575:820-5.

35. Liu Z, He T, Cao T, Yang T, Meng J, Chen W. Effects of biochar application on nitrogen leaching, ammonia volatilization and nitrogen use efficiency in two distinct soils. J Soil Sci Plant Nut. 2017;17(2):515-28.

36. Qiao D, Liu H, Yu L, Bao X, Simon GP, Petinakis E, Chen L. Preparation and characterization of slow-release fertilizer encapsulated by starch-based superabsorbent polymer. Carbohyd Polym. 2016;147:146-54.

37. Zheng W, Liu Z, Zhang M, Shi Y, Zhu Q, Sun Y, Zhou H, Li C, Yang Y, Geng J. Improving crop yields, nitrogen use efficiencies, and profits by using mixtures of coated controlled-released and uncoated urea in a wheat-maize system. Field Crop Res. 2017;205:106-15.

38. Puga AP, Grutzmacher P, Cerri CEP, Ribeirinho VS, Andrade CAD. Biocharbased nitrogen fertilizers: Greenhouse gas emissions, use efficiency, and maize yield in tropical soils. Sci Total Environ. 2020;704:13537.

\section{Publisher's Note}

Springer Nature remains neutral with regard to jurisdictional claims in published maps and institutional affiliations. 